Nelson, A., de Leon, A., Modeste, N., Marshak, H.H, Banta, J., Shah, H./ Californian Journal of Health Promotion 2018, Volume 16, Issue 2, Pages 32-43.

\title{
Association of Covered California and Healthcare Access and Utilization among Latino Population
}

\author{
Anna Nelson ${ }^{1}$, Aaron de Leon ${ }^{2}$, Naomi Modeste ${ }^{1}$, Helen Hopp Marshak ${ }^{1}$, \\ Jim Banta ${ }^{1}$, and Huma Shah ${ }^{1}$ \\ ${ }^{1}$ School of Public Health, Loma Linda University \\ ${ }^{2}$ Community Health Promotion Specialist, County of San Diego
}

\begin{abstract}
Background and Purpose: The Patient Protection and Affordable Care Act resulted in establishment of Covered California (Covered CA), a marketplace providing federally subsidized health insurance in California. This study explored whether obtaining Covered CA coverage improves healthcare access and utilization among Latinos, and whether acculturation plays a role in utilization of healthcare. Methods: 270 Latino adults in San Diego community completed a self-report survey. Results: Those with Covered CA were significantly more likely to have a main provider $(p<.0005)$, to select doctor's office as location for services $(p<.05)$, and significantly less likely $(p<.0005)$ to report cost as an obstacle to care compared to uninsured participants. The more acculturated group was more likely to report receiving care at a doctor's office $(p<.05)$. Those who were less acculturated were more likely to report cost as an obstacle to care $(p<.05)$. However, no significant associations were found between acculturation or insurance type and utilization of healthcare. Conclusion: Although health insurance and higher levels of acculturation do improve access, the study did not find their significant association with utilization of provider visits. Our results suggest that healthcare providers might want to consider additional factors to improve utilization of services instead of mainly emphasizing insurance.
\end{abstract}

(C) 2018 Californian Journal of Health Promotion. All rights reserved.

Keywords: Covered California, Affordable Care Act, Hispanics, Latino, access to care, health insurance, acculturation, utilization

\section{Introduction}

When the insurance mandate of the Affordable Care Act (ACA) took effect, health insurance became a requirement for most Americans due to the high number of uninsured individuals in the U.S. and the rising costs of health care. States received the opportunity to create health insurance exchanges to help with enrollment assistance (Kaiser Family Foundation, 2014). California is one of the states that chose to participate and established Covered California (Covered CA), the state's health insurance exchange. By increasing health insurance coverage and providing more opportunities for health care provider visits, Covered California's goal aims to increase access to care. However, there is no conclusive evidence on whether this increase in access through Covered CA actually results in increased utilization of health care services.
The enactment of Covered CA may have an important impact on Latino population because of the high rate of uninsured individuals in this group. Prior to the first enrollment of the healthcare exchange $36 \%$ of Latinos were uninsured; that rate dropped to $23 \%$ after the first enrollment, which lasted from January 2014 to March 2014 (Doty, Blumenthal, \& Collins, 2014). Studies in recent years show that ACA has led to improvements in healthcare access and affordability among low-income populations (Sommers, McMurtry, Blendon, Benson \& Sayde, 2017; Chen, Vargas-Bustamante, Mortensen, Ortega, 2016). In an Oregon-based study, Spanish-preferring Latinos had the largest increase in insurance coverage rate as a result of ACA (Heinzman, Bailey, DeVoe, Cowburn, Tapka, Duong, Marino, 2017). Limited studies have examined the effect of the ACA insurance 
Nelson, A., de Leon, A., Modeste, N., Marshak, H.H, Banta, J., Shah, H./ Californian Journal of Health Promotion 2018, Volume 16, Issue 2, Pages 32-43.

mandate on the actual utilization of healthcare services suggesting some reductions in disparities (Alcala, Chen, Langellier, Roby, Ortega, 2017; Wherry, Miller, 2016). This study evaluated the relationship of Covered CA or other insurance with healthcare access and utilization specifically among the Latino population. Additionally, previous research has suggested that those who are more acculturated tend to have higher rates of insurance and utilize medical services more than those who are less acculturated (Askim-Lovseth \& Aldana, 2010; Frank, Liebman, Ryder, Weir, \& Arcury, 2013), and we would like to explore this association in the Latino population for Covered CA and whether it is different from other categories of insurance.

\section{Purpose}

The objective of this study was to answer two questions:

1. Do San Diego community Latinos, who are enrolled in Covered CA, report different healthcare access and utilization compared to those who do not have any insurance or use a different type of insurance?

2. What is the relationship of acculturation with healthcare access and utilization among the Latino population using Covered CA plans and how it compares to that under other insurance categories?

\section{Methods}

\section{Study Design}

The study followed a cross-sectional design and used a self-report survey in English or Spanish to collect the participants' data. The survey was translated in Spanish by an individual bilingual in English and Spanish and piloted with individuals whose native language is Spanish. The dependent variables for this study included three separate questions for access and two separate questions for utilization of healthcare. The independent variable was the type of insurance and level of acculturation.

\section{Participants}

Latino adults $(N=270)$ from San Diego, California were recruited at a local health fair and two community Spanish churches. The convenience sample included 270 adults between the age of 18 and 78.

\section{Measures}

A self-report survey was constructed to evaluate the main variables of interest for this study. The questionnaire was piloted and adjusted based on the feedback received. The final survey was translated into Spanish and then approved by Loma Linda University's institutional review board. The participants completed an anonymous self-report survey in their choice of English or Spanish language providing information concerning their perceived access and utilization of health care services as well as their current insurance plan, if any.

Access to Care. Access was measured by three different variables: (a) main provider, (b) location of health services, and (c) obstacles to healthcare. Provider variable was a dichotomous 'yes' or 'no' variable. Location of health services was a categorical variable with the answer options of 'community clinic', 'doctor's office', or 'other'. The obstacles preventing participants from seeing a doctor were measured using three categories: 'no obstacles', 'too expensive or no insurance', 'all other'.

Utilization of Healthcare Services. Utilization was measured by two different variables: (a) time since last doctor visit and (b) delaying seeing a doctor. Three categories of responses for 'time since last doctor visit' included 'less than or equal to one year ago', 'greater than one year up to two years ago', or 'greater than two years ago'. Three categories of responses for delaying seeing a doctor were 'never', 'sometimes', or 'frequently'.

Type of Insurance. The main predictor variable was the type of insurance individuals used, which included three categories of responses: 'no insurance', 'Covered CA, or 'other insurance'. 'Other insurance' included Medi-Cal not obtained through Covered CA, employer-based insurance, Medicare, military health insurance and private insurance (not Covered CA). This was done to determine specifically the effect of Covered CA. Participants were thus classified into three groups according to their self-reported insurance status. 
Nelson, A., de Leon, A., Modeste, N., Marshak, H.H, Banta, J., Shah, H./ Californian Journal of Health Promotion 2018, Volume 16, Issue 2, Pages 32-43.

Level of Acculturation. This additional predictor variable was measured using five questions developed specifically for this survey and modeled after the California Health Interview Survey (CHIS). The responses to each of the five questions were dichotomized into 'more acculturated' or 'less acculturated' categories. Responses of 'very well', 'moderately well', or 'fairly well' to the question of how well the participant understands English in general were assigned a 'more acculturated' category. A response of 'English' as the primary language spoken at home was assigned to a 'more acculturated' category. A negative response to the question, whether a participant has a strong sense of being a member of the native culture of their ancestors, was assigned a 'more acculturated' category. A positive response to whether the participants consider themselves as U.S. American was assigned a more acculturated category. If a participant stated 'yes' to the question whether they feel that they are part of U.S. American culture, such response was also considered a 'more acculturated' response.

The variable was then calculated by the number of 'more acculturated' responses to the five questions. The overall score value of acculturation was then categorized into 'less acculturated', 'average acculturated' or 'more acculturated' levels. Scores of zero to one were designated as 'less acculturated'; two to three were designated as average level of acculturation; and four to five as 'more acculturated'.

Covariates. The covariates included in the survey were gender, BMI, age, primary language, Latino, ancestry of origin, country of birth, race and level of education. These covariates were obtained from demographic questions in the survey.

\section{Analyses}

Statistical analysis was conducted using SPSS version 22. Comparisons across the three different insurance groups were explored using a Kruskal-Wallis test for ordinal variables and a chi-square test for nominal variables to determine if there are significant associations at the bivariate level between the insurance group and each of the health care access and utilization outcome variables. To correct for the covariates, multinomial logistic regression was used for nominal or ordinal dependent variables with three or more groups, and binary logistic regression was employed for dichotomous dependent variables. These tests enabled us to determine whether the three types of insurance groups are significantly associated with any of the outcome variables.

\section{Results}

\section{Sample Characteristics}

Table 1 displays the demographic and clinical characteristics of the 270 Latino participants. There were more participants having no insurance (37\%) and other insurance types (42\%) compared to those having Covered CA (21\%). There were $73 \%$ female participants and $27 \%$ male participants, and their ages ranged from 18 to 78 years. More than half of the participants were born in Mexico (54\%) and had Spanish as their primary language (77\%). Forty-eight percent of participants were in the average acculturated group. Seventy percent of participants who had health insurance had it for more than 12 months. Forty-five percent of the participants reported a community clinic or a doctor's office as their primary source of care.

Table 2 presents the demographic characteristics of the participants, grouped by their health insurance status. Those who were uninsured were more likely to be born in Mexico $(p<.01)$ and have Spanish as their primary language $(p<.01)$. Those who had other insurance were more likely to be born in the U.S. $(p<.001)$ and not use Spanish as their primary language $(p<.001)$. Those who had no insurance were less likely to understand English very well $(p<.001)$, while those who had other insurance were more likely to understand English very well $(p<.01)$. Uninsured participants were more likely to have only completed grade school $(p<.001)$ and less likely to have completed a four-year college $(p<.05)$ or higher $(p<.01)$. Those who had other insurance were more likely to have completed a four-year college $(p<.05)$ or higher $(p<.01)$. 
Nelson, A., de Leon, A., Modeste, N., Marshak, H.H, Banta, J., Shah, H./ Californian Journal of Health Promotion 2018, Volume 16, Issue 2, Pages 32-43.

Table 1.

Demographic and Clinical Characteristics of the Participants

\begin{tabular}{|c|c|c|c|}
\hline & & $\mathrm{n}$ & $\%$ \\
\hline Age & & $37^{\mathrm{a}}$ & $60^{\mathrm{b}}$ \\
\hline \multirow[t]{2}{*}{ Gender } & Male & 72 & 27 \\
\hline & Female & 198 & 73 \\
\hline \multirow[t]{3}{*}{ Race } & White & 141 & 52 \\
\hline & Mixed & 34 & 13 \\
\hline & Other & 95 & 35 \\
\hline \multirow[t]{3}{*}{ Country of birth } & United States & 97 & $\overline{36}$ \\
\hline & Mexico & 147 & 54 \\
\hline & Other & 26 & 10 \\
\hline \multirow{6}{*}{$\begin{array}{l}\text { Highest grade of } \\
\text { education completed }\end{array}$} & did not complete grade school & 19 & 7 \\
\hline & grade school & 46 & 17 \\
\hline & high school & 72 & 27 \\
\hline & two-year community college & 41 & 15 \\
\hline & four-year college & 59 & 22 \\
\hline & graduate or professional school & 33 & 12 \\
\hline \multirow[t]{3}{*}{ Insurance group } & no insurance & 100 & 37 \\
\hline & Covered CA & 57 & 21 \\
\hline & other insurance & 113 & 42 \\
\hline \multirow[t]{3}{*}{ Level of acculturation } & less acculturated & 64 & $\overline{24}$ \\
\hline & average acculturated & 129 & 48 \\
\hline & more acculturated & 77 & 29 \\
\hline \multirow{2}{*}{$\begin{array}{l}\text { Presence of } \\
\text { main provider }\end{array}$} & Yes & 152 & $\overline{56}$ \\
\hline & No & 118 & 44 \\
\hline \multirow{3}{*}{$\begin{array}{l}\text { Location of health } \\
\text { services }\end{array}$} & community clinic & 122 & $\overline{45}$ \\
\hline & doctor's office & 122 & 45 \\
\hline & other (Pharmacy, ER) & 26 & 10 \\
\hline \multirow{3}{*}{$\begin{array}{l}\text { Preventing from } \\
\text { seeing a doctor }\end{array}$} & no obstacles & 138 & $\overline{51}$ \\
\hline & expensive/no insurance & 102 & 37 \\
\hline & all other & 30 & 11 \\
\hline \multirow{3}{*}{$\begin{array}{l}\text { Delaying seeing } \\
\text { a doctor }\end{array}$} & Never & 85 & $\overline{31}$ \\
\hline & Sometimes & 137 & 51 \\
\hline & frequently or more & 48 & 18 \\
\hline \multirow{3}{*}{$\begin{array}{l}\text { Time since last } \\
\text { doctor visit }\end{array}$} & one year ago or less & 194 & 72 \\
\hline & greater than one up to two & 40 & 15 \\
\hline & greater than two years ago & 36 & 13 \\
\hline \multirow{2}{*}{$\begin{array}{l}\text { Length of time } \\
\text { having insurance }\end{array}$} & less than or equal to 12 months & 49 & 30 \\
\hline & greater than 12 months & 116 & 70 \\
\hline
\end{tabular}

${ }^{\mathrm{a}}$ Median ${ }^{\mathrm{b}}$ Range 
Nelson, A., de Leon, A., Modeste, N., Marshak, H.H, Banta, J., Shah, H./ Californian Journal of Health Promotion 2018, Volume 16, Iscuo ? Р рппо २?-4?

Table 2.

Demographic Characteristics of the Different Health Insurance Groups

\begin{tabular}{|c|c|c|c|c|c|c|c|}
\hline & & No insurance & & & & $\mathrm{r}$ insu & rance \\
\hline & & $\mathrm{n}$ & $(\%)$ & $\mathrm{n}$ & $(\%)$ & $n$ & $(\%)$ \\
\hline Gender & male & 29 & (29) & 13 & (23) & 30 & (27) \\
\hline & female & 71 & (71) & 44 & (77) & 83 & (73) \\
\hline Race & white & 62 & (62) & 30 & (53) & 49 & (43) \\
\hline & mixed & 11 & (11) & 5 & (9) & 18 & (16) \\
\hline & other & 27 & $(27)$ & 22 & (39) & 46 & $(41)$ \\
\hline Country of & United States & 10 & $(10)^{* * *}$ & 25 & (44) & 62 & $(55)^{* * *}$ \\
\hline birth*** & Mexico & 77 & $(77)^{* *}$ & 29 & (51) & 41 & $(36) * * *$ \\
\hline & other & 13 & (13) & 3 & (5) & 10 & ( 9) \\
\hline Spanish primary & no & 10 & $(10)^{* *}$ & 8 & (14) & 44 & $(39)^{* * *}$ \\
\hline language*** & yes & 90 & $(90)$ & 49 & (86) & 69 & $(61)$ \\
\hline Understanding & very well & 27 & $(27)^{* * *}$ & 28 & (49) & 81 & $(72)^{* *}$ \\
\hline of English*** & moderately well & 31 & (31) & 20 & (35) & 24 & $(21)$ \\
\hline & not well & 42 & $(42) * * *$ & 9 & $(16)$ & 8 & $(7)^{* * *}$ \\
\hline Highest grade & not complete grade school & 11 & $(11)$ & 6 & (11) & 2 & $(2)^{*}$ \\
\hline of education & grade school & 31 & $(31)^{* * *}$ & 8 & (14) & 7 & $(6)^{* *}$ \\
\hline completed $* * *$ & high school & 31 & (31) & 22 & (39) & 19 & $(17)^{*}$ \\
\hline & two-year community college & 12 & $(12)$ & 9 & (16) & 20 & (18) \\
\hline & four-year college & 12 & $(12)^{*}$ & 9 & (16) & 38 & $(34)^{*}$ \\
\hline & graduate/professional school & 3 & $(3) * *$ & 3 & $(5)$ & 27 & $(24)^{* *}$ \\
\hline Ancestry of & Mexican & 96 & $(96)$ & 50 & (94) & 105 & $(93)$ \\
\hline origin & other Latino & 4 & (4) & 3 & $(6)$ & 8 & (7) \\
\hline Length of having & less or equal 12 months & 0 & $(0)$ & 29 & $(54)^{* *}$ & 20 & $(18)^{*}$ \\
\hline insurance $* * *$ & more than 12 months & 0 & $(0)$ & 25 & $(46)^{*}$ & 91 & $(82)$ \\
\hline Level of & less acculturated & 44 & $(44)^{* * *}$ & 11 & (19) & 9 & $(8)^{* * *}$ \\
\hline acculturation*** & average acculturated & 38 & (38) & 37 & (65) & 54 & $(48)$ \\
\hline & more acculturated & 18 & $(18)^{*}$ & 9 & $(16)$ & 50 & $(44)^{* *}$ \\
\hline BMI & & 28 & $(25)^{\mathrm{a}}$ & 29 & $(27)^{\mathrm{a}}$ & 27 & $(34)^{\mathrm{a}}$ \\
\hline Age & & 40 & $(52)^{a}$ & 33 & $(57)^{\mathrm{a}}$ & 35 & $(56)^{\mathrm{a}}$ \\
\hline
\end{tabular}

Those who had Covered CA were more likely to have insurance for less than a year $(p<.01)$. Those who had other insurance were less likely to have it for less than a year $(p<.05)$. Those who had no insurance were more likely to be less acculturated $(p<.001)$, while those who had other insurance were more likely to be more acculturated $(p<.01)$. There were no significant differences among insurance groups for gender, race, BMI and age.

\section{Healthcare Access Factors}

Table 3 shows the results of the bivariate analysis between the different insurance groups and the dependent variables. Those who had no insurance were less likely to have a main provider $(p<.001)$ and more likely to have a community clinic as a usual source of care $(p<.001)$ compared to those who had other insurance. Participants with no insurance were less likely to have no obstacles to care compared to those with other insurance $(p<.001)$ and more likely to have health care services out of reach due to expense than those with either Covered CA $(p<.01)$ or other insurance $(p<.001)$.

To determine if the significant relationships found between the different insurance groups and the various access factors was due to the insurance groups or due to any covariate, a multivariate analysis was performed (Table 4). Even when correcting for the covariates, those who have either Covered CA or other insurance are significantly more likely $(p<.001$ in both cases) to have a main provider compared to those with no insurance. 
Nelson, A., de Leon, A., Modeste, N., Marshak, H.H, Banta, J., Shah, H./ Californian Journal of Health Promotion 2018, Volume 16, Issue 2, Pages 32-43.

Table 3.

Bivariate Analysis of the Access Factors of Different Insurance Groups

\begin{tabular}{llllllll}
\hline & & \multicolumn{2}{l}{ No insurance } & \multicolumn{2}{c}{ Covered CA } & \multicolumn{2}{c}{ Other insurance } \\
\hline & & $\mathrm{n}$ & $(\%)$ & $\mathrm{n}$ & $(\%)$ & $\mathrm{n}$ & $(\%)$ \\
\hline Main provider*** & yes & 12 & $(12)^{* * *}$ & 41 & $(72)$ & 99 & $(88)^{* * *}$ \\
& no & 88 & $(88)^{* * *}$ & 16 & $(28)$ & 14 & $(12)^{* * *}$ \\
Location of health & community & 72 & $(72)^{* * *}$ & 34 & $(60)$ & 16 & $(14)^{* * *}$ \\
services*** & clinic & & & & & & \\
& doctor's office & 13 & $(13)^{* * *}$ & 18 & $(31)$ & 91 & $(81)^{* * *}$ \\
& other & 15 & $(15)$ & 5 & $(9)$ & 6 & $(5)$ \\
\hline $\begin{array}{l}\text { Preventing from seeing } \\
\text { doctor*** no obstacles }\end{array}$ & 12 & $(12)^{* * *}$ & 33 & $(58)$ & 93 & $(82)^{* * *}$ \\
& expensive/no & 82 & $(82)^{* * *}$ & 10 & $(17)^{* *}$ & 10 & $(9)^{* * *}$ \\
& ins & & & & & & \\
& all other & 6 & $(6)$ & 14 & $(25)^{* * *}$ & 10 & $(9)$ \\
\hline Delaying seeing a doctor never & 29 & $(29)$ & 15 & $(26)$ & 41 & $(36)$ \\
& sometimes & 47 & $(47)$ & 33 & $(58)$ & 57 & $(51)$ \\
& frequently & 24 & $(24)$ & 9 & $(16)$ & 15 & $(13)$ \\
\hline $\begin{array}{l}\text { Time since last doctor } \\
\text { visit*** }\end{array}$ & $\leq 1$ year ago & 58 & $(58)^{* * *}$ & 45 & $(79)^{*}$ & 91 & $(81)^{* * *}$ \\
& $1-2$ years & 18 & $(18)$ & 5 & $(9)$ & 17 & $(15)$ \\
& $>2$ years ago & 24 & $(24)^{* * *}$ & 7 & $(12)^{*}$ & 5 & $(5)^{* * *}$ \\
\hline
\end{tabular}

$* p<.05,{ }^{* *} p<.01, * * * p<.001$

analysis, those who had other health insurance

Those who had Covered CA were more likely $(O R=2.95, p<.05)$ and those who had other insurance were more likely $(O R=24.7, p<.001)$ to have a doctor's office as their source of care versus a community clinic than those who had no insurance. Those who had Covered CA or those with other insurance were less likely $(p<.001$ in both cases) to report cost as an obstacle compared to those who had no insurance. Thus, even after correcting for the covariates, there remains a significant association between having Covered CA or other insurance and the three health care access factors of having a main provider, location of health care services and obstacles to obtaining health care.

\section{Healthcare Utilization Factors}

There were no significant relationships identified between the three insurance groups and delaying in seeing a doctor. However, those individuals with no insurance were less likely to have seen a doctor within the last year compared to those with Covered CA $(p<.05)$ or those with other insurance $(p<.001)$ (Table 3$)$.

A multinomial logistic regression was performed to determine if the identified relationships were due to the different insurance groups or if they were due to one of the covariates (Table 4). In this compared to no insurance were $89 \%$ less likely to report visiting a health care provider greater than two years ago versus less than a year ago $(p<.01)$. No significant relationship, however, was found between Covered CA and no insurance with respect to time since last health care visit. Therefore, the significance found in the bivariate analysis was due to other covariates rather than the Covered CA insurance.

\section{The Influence of Acculturation on Access and Utilization}

Table 5 shows the results of the bivariate analysis between acculturation categories and the healthcare access factors. We found several significant relationships. The more acculturated group more frequently reported having a main provider $(p<.05)$, were less likely to report going to a community clinic as their source of care $(p<.05)$ and were more likely to report receiving care at a doctor's office $(p<.05)$ compared to those who were less acculturated. Those who were less acculturated were less likely to report no obstacles to care $(p<.05)$ and more likely to report cost as the obstacle to care $(p<.05)$, compared to those who were either in the average or more acculturated group. 
Nelson, A., de Leon, A., Modeste, N., Marshak, H.H, Banta, J., Shah, H./ Californian Journal of Health Promotion 2018, Volume 16, Issue 2, Pages 32-43.

Table 4.

Multivariate Analysis of Access Factors of Different Insurance Groups

\begin{tabular}{llcccc}
\hline & & \multicolumn{2}{c}{ Covered CA vs None } & \multicolumn{2}{c}{ Other insurance vs None } \\
\hline & & OR & $(95 \%$ CI $)$ & OR & $(95 \%$ CI $)$ \\
\hline Main provider & Yes vs No & $60.2^{* * *}$ & $(16.8,215)$ & $99.3^{* * *}$ & $(26.8,368)$ \\
Location of & Dr's Office vs Clinic & $2.95^{*}$ & $(1.04,8.38)$ & $24.7^{* * *}$ & $(8.47,72.1)$ \\
health services & Other vs Community Clinic & 1.04 & $(0.28,3.88)$ & 1.66 & $(0.41,6.73)$ \\
\hline Preventing from & Too Expensive vs No Obstacles & $0.04^{* * *}$ & $(0.01,0.13)$ & $0.01^{* * *}$ & $(0.00,0.03)$ \\
seeing a doctor & Other Reasons vs No Obstacles & 1.13 & $(0.27,4.82)$ & 0.30 & $(0.06,1.51)$ \\
\hline Time since last & $>2$ yrs vs $\leq 1$ yr & 0.37 & $(0.10,1.33)$ & $0.11^{* *}$ & $(0.25,0.48)$ \\
doctor visit & $1-2$ yrs vs $\leq 1$ yr & 0.32 & $(0.09,1.18)$ & 0.83 & $(0.29,2.36)$ \\
\hline General health & Excellent vs Poor Health & 4.11 & $(0.61,27.6)$ & $13.3^{*}$ & $(1.26,140)$ \\
& Very Good vs Poor Health & 0.73 & $(0.15,3.55)$ & 6.88 & $(0.91,51.1)$ \\
& Good vs Poor Health & 1.15 & $(0.26,5.07)$ & 3.28 & $(0.49,24.0)$ \\
& Fair vs Poor Health & 0.86 & $(0.19,3.91)$ & 2.23 & $(0.29,17.2)$ \\
\hline
\end{tabular}

$* p<.05, * * p<.01, * * * p<.001$

Table 5.

Bivariate Analysis of the Access Factors of Different Acculturation Levels

Less acculturated Average acculturated More acculturated

\begin{tabular}{llcccccc}
\hline & & $\mathrm{n}$ & $(\%)$ & $\mathrm{n}$ & $(\%)$ & $\mathrm{n}$ & $(\%)$ \\
Insurance & no insurance & 44 & $(69)^{* * *}$ & 38 & $(29)$ & 18 & $(23)^{*}$ \\
groups*** & Covered CA & 11 & $(17)$ & 37 & $(29)$ & 9 & $(12)$ \\
& other insurance & 9 & $(14)^{* * *}$ & 54 & $(42)$ & 50 & $(65)^{* * *}$ \\
\hline Main & yes & 21 & $(33)^{*}$ & 74 & $(57)$ & 57 & $(74)^{*}$ \\
provider*** & no & 43 & $(67)^{* *}$ & 55 & $(43)$ & 20 & $(26)^{* *}$ \\
\hline Location of & community clinic & 39 & $(61)$ & 62 & $(48)$ & 21 & $(27)^{*}$ \\
health & doctor's office & 14 & $(22)^{* *}$ & 59 & $(46)$ & 49 & $(64)^{*}$ \\
services*** & other & 11 & $(17)$ & 8 & $(6)$ & 7 & $(9)$ \\
\hline Preventing from & no obstacles & 20 & $(31)^{*}$ & 71 & $(55)$ & 47 & $(61)$ \\
seeing a & expensive/no ins & 36 & $(56)^{*}$ & 44 & $(34)$ & 22 & $(29)$ \\
doctor** & all other & 8 & $(13)$ & 14 & $(11)$ & 8 & $(10)$ \\
\hline Delay & never & 20 & $(31)$ & 43 & $(33)$ & 22 & $(28)$ \\
seeing a doctor & sometimes & 34 & $(53)$ & 64 & $(50)$ & 39 & $(51)$ \\
& frequently & 10 & $(16)$ & 22 & $(17)$ & 16 & $(21)$ \\
\hline Time since last & $\leq$ year ago & 41 & $(64)$ & 94 & $(73)$ & 59 & $(77)$ \\
doctor visit & $1-2$ years & 12 & $(19)$ & 15 & $(12)$ & 13 & $(17)$ \\
& $>2$ years ago & 11 & $(17)$ & 20 & $(15)$ & 5 & $(6)$ \\
\hline
\end{tabular}

${ }^{*} p<.05, * * p<.01, * * * p<.001$

There was a significant relationship between acculturation and insurance type. The more acculturated group had fewer cases of no insurance $(p<.05)$ and more cases of other insurance $(p<.001)$, compared to the less

acculturated group. No significant association was found between acculturation and Covered CA. There was also no association between

acculturation and any of the utilization factors: time since last visit and delay in visiting a health care provider. Thus, acculturation was associated with an improvement in access to care but not with utilization.

\section{Discussion}

Our study suggests that Latinos in one community of San Diego who are enrolled in a 
Nelson, A., de Leon, A., Modeste, N., Marshak, H.H, Banta, J., Shah, H./ Californian Journal of Health Promotion 2018, Volume 16, Issue 2, Pages 32-43.

Covered CA health insurance plan report that cost is less of an obstacle to care, compared to those who did not enroll in health insurance. This corroborates the findings of Burge and Schade (2014) that the federal government Covered CA subsidies decrease the costs of health care services to individuals.

The study also showed that individuals enrolled in other health insurance plans not under Covered CA also report better access factors compared to those with no insurance. These factors include the presence of a main provider, using a doctor's office and having no obstacles to care. Our findings corroborate those of De Jesus and Xiao (2013) who report that individuals without health insurance are less likely to have a primary source of care compared to those who are insured. Approximately 25\% of Latino adults report not having a main provider to treat their medical needs (De Jesus \& Xiao, 2013). Similarly, our findings demonstrate that those without insurance have a difficult time obtaining a main provider even though they report going to a community clinic as their source of care. These findings are also in agreement with Frank et al. (2013), as individuals without insurance delay seeking health care services until their health becomes dire. At this point, however, community clinics may not able to provide them the care they need, as many secondary and tertiary health care services cannot be performed by primary care doctors (Frank et al., 2013).

Ortega, Rodriguez, and Vargas Bustamante (2015) found that individuals with insurance who receive care at community clinics report that the quality is comparable to that received in other settings. Although our study did not look at the quality difference, our study is in agreement with Ortega et al. (2015) in that major deficits in quality have been reported for uninsured individuals who receive care at community clinics as they are less integrated into a usual source of care.

While our results show that Covered CA provides more opportunities for individuals to obtain health insurance, this does not eliminate all barriers to health care access due to factors such as financial, language and cultural barriers
(Nahin, Dahlhamer, \& Stussman, 2010; Balcazar et al., 2015; Castañeda \& Melo, 2014; Becerra, Androff, Messing, Castillo, \& Cimino, 2015). Our findings show that those with Covered CA report having cost as an obstacle to care more than those with other insurance. This may be because, as demonstrated in other studies, those with other insurance have their employers either pay for their health insurance or have lower deductibles and copayments than those with Covered CA (Ortega et al., 2015; Ziemer et al., 2014). Karpman, Weiss, and Long (2015) found that low-income adults continue to have the most difficulty with provider access and these individuals were also $6 \%$ more likely to be Latino. Also, in our study, those with other insurance had fewer obstacles to care than those with Covered CA. This may be because they have been enrolled in their health insurance plan for a longer period of time, which afforded them more opportunities to become familiar with the health care system.

The findings that there were no significant relationships found among the three insurance groups and the delay in seeing a doctor is important because although health insurance is available, individuals may not be utilizing their health insurance to seek health care services when they need it. There are many factors involved, such as not having a usual place of care, not having a regular provider, mistrust of providers, the type and proximity of the health care facility to their place of residence, and not understanding the U.S. health care system (Ai, Noël, Appel, Huang, \& Hefley, 2013; De Jesus \& Xiao, 2014). In a study using the 2007 Pew Hispanic Healthcare Survey of over 4,000 Hispanic adults, De Jesus \& Xiao (2014) found that those who had continuous health insurance during the past year saw a doctor sooner compared to those without insurance $(p<.05)$. This finding was not supported in our study.

Many Latinos do not have the financial ability to afford the out-of-pocket costs of care even with insurance (Escarce \& Kapur, 2006). Although Latinos often forgo medical care due to cost, they also do so because they prefer services that reflect their culture (Titus, 2014). Titus (2014) found that approximately 6\% of Latinos seek a healer a curandero for their health care needs mainly for 
Nelson, A., de Leon, A., Modeste, N., Marshak, H.H, Banta, J., Shah, H./ Californian Journal of Health Promotion 2018, Volume 16, Issue 2, Pages 32-43.

affordability purposes but also for language needs, fear of deportation, and for culturally appropriate heath care. These factors may contribute to the decision of Latinos to delay utilizing health care services when there is a perceived need and might serve as an explanation of our findings that Covered CA does not increase utilization of health care services.

Thus, when corrected for the covariates, the time between health care provider visits did not differ significantly between individuals with health insurance obtained through Covered CA and those uninsured. More research is needed to determine what methods are effective to educate and encourage people to utilize their health insurance.

Less acculturated Latinos in our study were less likely to have a main provider, since they lack health insurance, which is in agreement with Askim-Lovseth and Aldana (2010). More acculturated Latinos reported having other type of health insurance besides Covered CA likely due to having jobs that offer health benefits. These results are corroborated by De Jesus and Xiao (2013) who state that about $30 \%$ of all Latino adults work for an employer who does not offer health insurance compared to $13 \%$ of Whites. In addition, second or later immigrant generations, with deeper familial roots in the U.S., are more likely to have health insurance and a usual source of care than first immigrant generations due to more cultural and social capital as well as more English language proficiency (Balcazar, Grineski, \& Collins, 2015; Teruya \& Bazargan-Hejazi, 2013; Padilla et al., 2011).

In our study, those who are less acculturated have reported more obstacles to care than those who are average or more acculturated due to cost of health insurance and health care services, which include monthly premiums, copayments and deductibles. This is in agreement with Balcazar et al. (2015), who found in a survey of over 1,900 Latino adults in Texas that second and higher generations were significantly more likely not to have problems with cost when seeking health care services. They also found that this group was significantly more likely to have a regular doctor and more likely to be continuously insured during the last 12 months compared to first generation noncitizens.

Our findings demonstrate that health insurance contributes to better access specifically in the ability to have a main provider, to have a doctor's office as the main source of care and for preventing obstacles to care. Higher rates of healthcare access among those with insurance may be a result of the lower costs of healthcare services, greater availability of resources, and a more structured pathway to services. In addition, lower acculturated Latinos are more likely to be less educated and have lower incomes than more acculturated individuals and this may play a role in explaining our results of the inability to access health care services (Padilla et al., 2011). Thus, although acculturation promotes better access, it has no influence on any of the utilization factors of time since last visit or delay in seeing a healthcare provider. These associations or rather the lack of them certainly warrant further investigation. One factor that can be further explored is the lack of utilization due to a lack of need of healthcare services in the Latino population.

Although we demonstrated that health insurance and higher levels of acculturation do improve access, having Covered CA insurance does not improve utilization, as there are neither increased provider visits nor differences in delay of care compared to not having insurance. Those specifically with Covered CA insurance healthcare plans did not report higher rates of utilization possibly because despite the insurance they still cannot afford the costs of healthcare services and may have a difficult time establishing care, since not all providers accept all Covered CA plans.

\section{Limitations}

One of the study limitations is that since this study relied only on an observational design, any associations between insurance group and outcome could be due to other factors such as religious beliefs, personality traits, mental health status, and location of residence. Mono-method bias is a threat to internal validity of the study, as 
Nelson, A., de Leon, A., Modeste, N., Marshak, H.H, Banta, J., Shah, H./ Californian Journal of Health Promotion 2018, Volume 16, Issue 2, Pages 32-43.

we collected the data mainly by one written survey. Selection bias may exist because the people who agreed to complete the survey might have been more interested in their health than those who declined to participate (Shadish, Cook, \& Campbell, 2002). As this was a short survey, the questions were limited and could not measure the intricacies of key constructs such as acculturation. Finally, as the study was conducted in one geographical location, these results may not be generalizable to a larger Latino population in the U.S.

\section{Conclusion}

The study aimed to determine whether a type of insurance or a level of acculturation were associated with improved healthcare utilization and access among Latinos in San Diego community. Based on the results, there is an evidence of association between having a healthcare insurance plan and access to healthcare services, as well as higher acculturation and access to healthcare services. The findings did not, however, support that either insurance type or acculturation level corresponded with the improved utilization of healthcare services in this group. The improved access appears to fail to translate into an improvement in utilization.

As a result, health care providers might want to consider factors involved in improving utilization of services for individuals with Covered CA insurance instead of only emphasizing insurance enrollment. By evaluating these conclusions, health educators might be alerted to the possibility that access through Covered CA does not automatically equate to improved utilization. Further studies are warranted to determine what other factors could contribute to improving utilization of healthcare services.

\section{References}

Ai, A. L., Noël, L. T., Appel, H. B., Huang, B., \& Hefley, W. E. (2013). Overall health and health care utilization among Latino American men in the United States. American Journal of Men's Health, 7(1), 6-17. doi:10.1177/1557988312452752

Alcalá, H. E., Chen, J., Langellier, B. A., Roby, D. H., \& Ortega, A. N. (2017). Impact of the Affordable Care Act on health care access and utilization among Latinos. The Journal of the American Board of Family Medicine, 30(1), 52-62.

Askim-Lovseth, M. K., \& Aldana, A. (2010). Looking beyond "affordable” health care: Cultural understanding and sensitivity-necessities in addressing the health care disparities of the U.S. Hispanic population. Health Marketing Quarterly, 27, 354-387. doi: 10.1080/07359683.2010.519990

Balcazar, A. J., Grineski, S. E., \& Collins, T. W. (2015). The durability of immigrationrelated barriers to health care access for Hispanics across generations. Hispanic Journal of Behavioral Sciences, 37(1), 118-135. doi:10.1177/0739986314567074

Becerra, D., Androff, D., Messing, J. T., Castillo, J., \& Cimino, A. (2015). Linguistic acculturation and perceptions of quality, access, and discrimination in health care among Latinos in the United States. Social Work in Health Care, 54(2), 134-157. doi:10.1080/00981389.2014.982267

Burge, M. R., \& Schade, D. S. (2014). Diabetes and the Affordable Care Act. Diabetes Technology and Therapeutics, 16, 7. doi: 10.1089/dia.2014.0171

Castañeda, H., \& Melo, M. A. (2014). Health care access for Latino mixed-status families: Barriers, strategies, and implications for reform. American Behavioral Scientist, 58(14), 1891-1909. doi:10.1177/0002764214550290

Chen, J., Vargas-Bustamante, A., Mortensen, K., \& Ortega, A. N. (2016). Racial and ethnic disparities in health care access and utilization under the Affordable Care Act. Medical care, 54(2), 140.

De Jesus, M., \& Xiao, C. (2013). Cross-border health care utilization among the Hispanic population in the United States: Implications for closing the health care access gap. Ethnicity \& Health, 18(3), 297-314. doi:10.1080/13557858.2012.730610 
Nelson, A., de Leon, A., Modeste, N., Marshak, H.H, Banta, J., Shah, H./ Californian Journal of Health Promotion 2018, Volume 16, Issue 2, Pages 32-43.

De Jesus, M., \& Xiao, C. (2014). Predicting health care utilization among Latinos: Health locus of control beliefs or access factors? Health Education \& Behavior, 41, 423-430. doi: $10.1177 / 1090198114529130$

Doty, M. M., Blumenthal, D., \& Collins, S. R. (2014). The Affordable Care Act and health insurance for Latinos. The Journal of the American Medical Association. Advance online publication. doi: 10.1001/jama.2014.13841

Escarce, J. J., \& Kapur, K. (2006). Access to and quality of health care. Retrieved from http://www.ncbi.nlm.nih.gov/books/NBK19910/

Frank, A. L., Liebman, A. K., Ryder, B., Weir, M., \& Arcury, T. A. (2013). Health care access and health care workforce for immigrant workers in the agriculture, forestry, and fisheries sector in the southeastern U.S. American Journal of Industrial Medicine, 56, 960-974. doi: 10.1002/ajim.22183

Heintzman, J., Bailey, S. R., DeVoe, J., Cowburn, S., Kapka, T., Duong, T. V., \& Marino, M. (2017). In low-income Latino patients, post-Affordable Care Act Insurance disparities may be reduced even more than broader national estimates: evidence from Oregon. Journal of racial and ethnic health disparities, 4(3), 329-336.

IBM Corp. Released 2013. IBM SPSS Statistics for Windows, Version 22.0. Armonk, NY: IBM Corp.

Kaiser Family Foundation. (2014). Medicaid moving forward. Retrieved from http://kff.org/medicaid/fact-sheet/the-medicaid-program-at-a-glance-update/

Karpman, M., Weiss, A., \& Long, S. (2015). QuickTake: Access to health care providers

improved between September 2013 and September 2014. Retrieved from http://hrms.urban.org/quicktakes/Access-to-Health-Care-Providers-Improved.html

Nahin, R., Dahlhamer, J., \& Stussman, B. (2010). Health need and the use of alternative medicine among adults who do not use conventional medicine. BMC Health Services Research, 10, 22. doi:10.1186/1472-6963-10- 220

Ortega, A. N., Rodriguez, H. P., \& Vargas Bustamante, A. (2015). Policy dilemmas in Latino health care and implementation of the Affordable Care Act. Annual Review of Public Health, 36(1), 525-544. doi:10.1146/annurev-publhealth031914-122421

Padilla, R., Steiner, J. F., Havranek, E. P., Beaty, B., Davidson, A. J., \& Bull, S. (2011). A comparison of different measures of acculturation with cardiovascular risk factors in Latinos with hypertension. Journal of Immigrant and Minority Health, 13, 284-292. doi: 10.1007/s10903-010-9434-5

Shadish, W. R., Cook, T. D., \& Campbell, D. T. (2002). Experimental and Quasi-experimental Designs for Generalized Causal Inference. Boston: Houghton Mifflin.

Teruya, S. A., \& Bazargan-Hejazi, S. (2013). The immigrant and hispanic paradoxes: A systematic review of their predictions and effects. Hispanic Journal of Behavioral Sciences, 35(4), 486-509.

Titus, S. K. F. (2014). Seeking and utilizing a curandero in the United States: A literature review. Journal of Holistic Nursing, 32(3), 189-201.

Wherry, L. R., \& Miller, S. (2016). Early coverage, access, utilization, and health effects associated with the Affordable Care Act Medicaid expansions: a quasi-experimental study. Annals of internal medicine, 164(12), 795-803.

Ziemer, C., Becker-Dreps, S., Pathman, D., Mihas, P., Frasier, P., Colindres, M., . . . Robinson, S. (2014). Mexican immigrants' attitudes and interest in health insurance: A qualitative descriptive study. Journal of Immigrant \& Minority Health, 16(4), 724732. doi:10.1007/s10903-013-9794-8 
Nelson, A., de Leon, A., Modeste, N., Marshak, H.H, Banta, J., Shah, H./ Californian Journal of Health Promotion 2018, Volume 16, Issue 2, Pages 32-43.

\author{
Author Information \\ Anna Nelson, DrPH, CHES - Corresponding Author* \\ Assistant Professor, Health Promotion and Education \\ School of Public Health, Loma Linda University \\ E-mail: anelson@llu.edu
}

